\title{
The use of pharmacotherapies for smoking cessation during pregnancy
}

\author{
Neal L Benowitz, Delia A Dempsey, Robert L Goldenberg, John R Hughes, \\ Patricia Dolan-Mullen, Paul L Ogburn, Cheryl Oncken, C Tracy Orleans, \\ Theodore A Slotkin, H Pennington Whiteside, Jr, Sumner Yaffe
}

Departments of Medicine, Psychiatry, and

Biopharmaceutical

Sciences, University of

California-San

Francisco, San

Francisco, California, USA

N L Benowitz

Department of Pediatrics, University of California-San

Francisco

D A Dempsey

Smoke-Free Families Program, Department of Obstetrics and Gynecology, University of Alabama at Birmingham, Birmingham, Alabama, USA R L Goldenberg R L Goldenberg
H P Whiteside, Jr

Department of Psychiatry, University of Vermont, Burlington, Vermont, USA

J R Hughes

Center for Health Promotion Research and Prevention, University of

Texas-Houston Health Science Center, School of Public Health,

Houston, Texas, USA

P Dolan-Mullen

Department of

Obstetrics and

Gynecology, Mayo

Medical School,

Rochester, Minnesota,

USA

P L Ogburn

Department of Medicine, University of Connecticut Health Center, Farmington, Connecticut, USA C Oncken

Research and Evaluation Unit, The Robert Wood Johnson Foundation,

Princeton, New Jersey, USA

C T Orleans
A workshop entitled "The use of pharmacotherapies for smoking cessation during pregnancy", sponsored by the National Institute of Child Health and Human Development (NICHD) and the Robert Wood Johnson Foundation (RWJF), was held in Rockville, Maryland, on 19 May 1999. The goals of the workshop were: (1) to determine the current state of knowledge related to the use of pharmacotherapies for smoking cessation during pregnancy; and (2) to outline a research agenda to determine the effectiveness and safety of these pharmacotherapies. Attending the workshop were many of the academic experts working in this area in the USA and representatives from NICHD, RWJF, the National Cancer Institute (NCI), the National Institute of Drug Abuse (NIDA), the Food and Drug Administration (FDA), the Centers for Disease Control and Prevention (CDC), the American College of Obstetrics and Gynecology (ACOG), the Society for Research on Nicotine and Tobacco (SRNT), and several pharmaceutical companies.

\section{Background}

In the USA, of the four million women who deliver babies each year, approximately $0.8-1$ million smoke during their pregnancies. Smoking has a substantial adverse impact on pregnancy outcomes including growth retardation, preterm birth, perinatal mortality, sudden infant death syndrome (SIDS), and childhood behavioural problems. In developed countries, more than a third of all cases of growth retardation is caused by maternal smoking, and the more a woman smokes, the larger the effect on fetal growth. Stopping smoking is one of the major preventive measures likely to have a substantial impact on improving pregnancy outcome. Smoking most likely achieves its negative impact on pregnancy outcome through a number of mechanisms. These include the following: (1) nicotine is a toxin at the cellular level and also may act through its vasoconstrictive properties; (2) carbon monoxide - a major byproduct of cigarette smoking - binds to haemoglobin, resulting in a functional maternal anaemia; (3) carbon monoxide also reduces the amount of oxygen transferred from maternal to fetal blood, and produces hypoxia in fetal tissue; (4) numerous cigarette smoke components are cellular toxins (carbon monoxide, nicotine, cyanide, cadmium, lead, methanol, and many others); and (5) smoking may also alter the maternal/fetal nutritional status.

Behavioural interventions are effective in reducing smoking during pregnancy. A meta-analysis of 16 randomised controlled smoking cessation trials during pregnancy with validated outcomes confirms that a single 5-15 minute counselling session by a trained provider with appropriate printed materials approximately doubles the typical cessation rates of 5-10\% achieved without counselling to about $20 \%{ }^{1}$ This increased level in cessation is associated with a reduction in low birth weight and is estimated to save $\$ 3$ in medical costs for every $\$ 1$ spent on the intervention. ${ }^{2}$ Unfortunately, brief counselling does not achieve cessation in the remaining $80 \%$ of pregnant smokers, is least effective in the most dependent smokers, and may not be acceptable to some pregnant women. Studies testing more intensive counselling-more time and more occasions-have not generally achieved larger effects. Thus, it is unlikely that additional behavioural interventions used alone will achieve a substantial increase in cessation in pregnant smokers.

\section{Components of cigarette smoke}

Cigarette smoking during pregnancy is associated with a number of adverse outcomes; however, it is unclear which components of cigarette smoke actually do the damage. In addition to nicotine, cigarette smoke contains carbon monoxide, cyanide, aniline, methanol, hydrogen sulfide, arsenic, lead, cadmium, and 3000 other potential toxins or carcinogens. While most of the studies of the fetal effects of smoking have focused on nicotine, it is unknown which other components of smoke actually lead to some or all of the known adverse outcomes.

Nicotine activates the sympathetic nervous system and evokes the release of catecholamines and other neurotransmitters. ${ }^{3}$ In animal fetuses, nicotine administered by osmotic minipump to simulate transdermal patch application can reduce overall fetal growth and produce some neurologic abnormalities secondary to perturbation of neuronal maturation and neuronal cell death. ${ }^{4}$ In the first trimester, even short term 
Department of Pharmacology \& Cancer Biology, Duke University Medical Center, Durham, North Carolina, USA T A Slotkin

Center for Research on Mothers and Children, National Institute for National Institute Human Development, Bethesda, Maryland, USA

S Yaffe

Correspondence to: H Pennington Whiteside, Jr, MSPH, Smoke-Free Families National Program Office, University of Alabama at Birmingham, School of Medicine, Department of Medicine, Department of 320 CIRC, 1530 3rd Avenue South, Birmingham, AL 35294-0021, USA; hpw@uab.edu nicotine exposure can elicit neuronal cell death. ${ }^{6}$ Also in study animals, the impact of nicotine is related to the time in pregnancy when it is administered, the dosage level, and whether it is given intermittently or by continuous infusion. The adverse effects of nicotine were worse in the presence of even mild hypoxia. In animals, nicotine-used alone in doses similar to nicotine blood concentrations associated with smoking or nicotine replacement therapy (NRT) - can cause abortion and fetal death, growth retardation, and a decrease in fetal brain growth. ${ }^{5-7}$ In humans, nicotine is associated with increased heart rate and vasoconstriction. There is no evidence that in the usual dosage range, nicotine, even when used early in pregnancy, is dysmorphogenic.

Aside from nicotine, carbon monoxide has been the most studied component of cigarette smoke. In animals, chronic carbon monoxide exposure resulting in carboxyhaemoglobin concentrations in the range found in human smokers is associated with fetal growth retardation. Postnatal effects in animals associated with prenatal carbon monoxide exposure are similar to the spectrum of effects seen with nicotine (alterations in behaviour and cognition, neurotransmitter changes in the central nervous system, decreased cerebellar weight, etc). One likely benefit of NRT as an alternative to smoking is to spare the fetus exposure to carbon monoxide.

\section{Possible effects of pharmacotherapies}

In non-pregnant smokers, NRT, whether administered by gum, patch, inhaler or nasal spray, and antidepressant drugs, such as bupropion and nortriptyline, have all achieved a twofold increase in cessation rates compared to placebo medications. ${ }^{8-11}$ In non-pregnant smokers, when used according to instructions, NRT in any form and bupropion are generally safe. Therefore, pharmacologic treatments have the potential for achieving an important reduction in smoking during pregnancy. However, the use of pharmacologic agents in pregnancy raises at least two concerns. ${ }^{12}$ First, the developing fetus is at risk for teratogenic, asphyxic, and neurodevelopmental damage. Second, pregnancy itself is a powerful motivator for cessation, with a substantial number of women quitting spontaneously or with behavioural therapy. Whether pharmacologic treatment is safe for the fetus, and whether pharmacologic treatment will be as effective in achieving cessation in pregnant smokers compared to non-pregnant smokers, is unknown. Another significant gap in our knowledge concerns the optimal dose of nicotine and the response to the drug in pregnant women. ${ }^{9}$

Currently in the USA, nicotine gum and patch are available over-the-counter with a warning to not use during pregnancy without consulting a physician. Nicotine inhaler and nasal spray are available by prescription and have a category $\mathrm{D}$ pregnancy warning (that is, "There is positive evidence of human fetal risk, but benefits from the use during pregnancy may be acceptable despite the risk ...”). ${ }^{13}$ The package inserts on these products state that ". . . pregnant smokers should be encouraged to attempt cessation using educational and behavioural interventions before using pharmacological approaches" and these therapies " . . .should be used during pregnancy only if the likelihood of smoking cessation justifies the potential risk of using it by the pregnant patient, who might continue to smoke" ${ }^{14}$

There are several unanswered questions about nicotine safety in pregnancy: (1) whether there is a critical period of exposure to nicotine that increases the risk of fetal or obstetrical toxicity; (2) whether there is a dose threshold of toxicity; (3) whether a better pharmacokinetic model of fetal exposure to nicotine from smoking can be developed; and (4) whether a biomarker of nicotine effect on neural development in neonates could be discovered to assess some of the potential toxic effects of nicotine in vivo. ${ }^{15}$

Bupropion and nortriptyline-antidepressant medicines - increase dopamine and noradrenaline activity. ${ }^{11}$ However, the mechanisms by which these medications aid in smoking cessation are unknown. Since these medications achieve similar levels of cessation in depressed and non-depressed smokers, the mechanism of action is not completely related to their action as antidepressants. There are no data on the safety of bupropion or nortriptyline for smoking cessation during pregnancy. Bupropion is classified as a pregnancy category $B$ medication (that is, animal studies have shown no risk without confirmation in human studies, or animal studies have shown risk but controlled studies in humans showed no risk), ${ }^{13}$ and nortriptyline is listed as a category $\mathrm{D}$ medication.

Almost no efficacy research related to the use of NRT in pregnant human subjects has been conducted. One large efficacy study of NRT (nicotine patch) use by pregnant women was carried out in Scandinavia; however, to date, the results have not been published and only an abstract - without outcome data-is available. ${ }^{16}$ An oral presentation of this study suggested that NRT (nicotine patch) was not effective. ${ }^{16}$ There are no other randomised studies; thus, no decision on the efficacy of NRT in pregnancy can be made at this time. Two small clinical trials in pregnant women suggest short term use of NRT administered by commercially available patches or gum achieved serum nicotine concentrations comparable or less than those obtained while smoking 10-20 cigarettes per day. ${ }^{17-19}$ Among these few pregnant women, there were no adverse outcomes to the mother or fetus, although nicotine apparently has effects on fetal breathing movements and on fetal heart rate variability. ${ }^{19}$ Because of the small number of pregnant smokers studied to date, rare or subtle adverse fetal outcomes would not likely have been detected.

No conclusion could be reached as to whether the effects of intermittent dosing of nicotine - such as achieved by smoking - were different than steady state delivery such as 
achieved with the nicotine patch. Some discussants expressed concern about potential harm to a fetus continually exposed to nicotine with no rest period as would occur with a 24 hour patch. Some discussants believed that it was unlikely that delivering concentrations of nicotine by NRT that are similar to those seen in smokers would increase the risk of adverse outcomes over those seen in women who smoke, given that pregnant smokers are exposed not only to nicotine but also to the many other toxins in tobacco smoke. Others emphasised that high dose patches might deliver higher doses of nicotine and at a higher constant concentration than that seen in many-and especially light-smokers. The major adverse effects of smoking, especially those related to birth weight, appear to occur late in pregnancy. It was hypothesised that with NRT, the potential adverse side effects in terms of fetal growth would also occur late in pregnancy. Several participants therefore suggested that if NRT were used, it should be started earlier rather than later in pregnancy.

\section{Research needed}

Both basic research and clinical outcomes research are necessary to determine whether pharmacologic treatment of pregnant smokers is safe and effective. ${ }^{9}$ Further work in experimental animals is necessary to answer questions related to the influence of dose, time, pattern of administration on the adverse effects of nicotine, carbon monoxide, and other components of tobacco smoke. It is also important to determine the specific effects of the tobacco smoke components (for example, nicotine versus carbon monoxide versus others) on maternal blood flow, placental development and function, and on fetal somatic cell growth and brain development.

Equally important is the study of the efficacy of various NRT strategies and antidepressants in pregnant smokers. Effectiveness studies that deal with acceptability in actual use are also important. Since reduction in the absence of cessation is common in pregnancy, further investigation of both smoking cessation and reduction are indicated, as well as measures of fetal growth such as mean birth weight, the per cent small-for-gestational-age infants $(<10$ th centile), and preterm birth. The impact of pharmacotherapies on rarer outcomes such as abruption and fetal death would require a very large sample size. Outcomes, such as infant neurodevelopmental status at ages 2 to 5 years, as well as growth status at the same ages, are important but difficult to study.

The interaction between pharmacologic agents and various behavioural interventions also needs further study. A randomised factorial design contrasting a behavioural method versus brief advice and a pharmacologic intervention versus placebo is needed. A related issue is that if the prenatal care provider waits for a woman to fail a behavioural therapy before presenting pharmacotherapy, this may result in medication being used later rather than early in pregnancy. As stated earlier, there is reason to prefer the opposite. Other important questions to explore include when during pregnancy to initiate pharmacologic treatment and for how long to maintain its use.

NRT efficacy studies should monitor, in a standardised manner, known adverse pregnancy outcomes associated with smoking during pregnancy. Although large sample sizes would be needed to detect differences in risk for any one outcome, by combining standardised outcomes (that is, low birth weight, premature delivery, abruptio placenta, placenta previa, SIDS, etc) across studies, it may be possible to estimate the safety of NRT compared to placebo for smoking cessation during pregnancy. This type of safety study has been done to determine the safety of NRT in cardiac patients. ${ }^{20}$

\section{Conclusions}

Despite the absence of data on safety, efficacy, and effectiveness, the use of pharmacologic agents in pregnancy is becoming increasingly considered, given the increased awareness of the harm from smoking in pregnancy and the benefits of pharmacotherapy. Given the large attributable risk of adverse outcomes in pregnancy associated with cigarette smoking, the current over-the-counter status of NRT, and the potential for substantial benefit in reducing adverse pregnancy outcomes using pharmacologic agents, clinical studies in this area should be undertaken immediately.

Other workshop participants (in alphabetical order): Cathy Backinger, MPH, PhD, National Cancer Institute (NCI), National Institutes of Health (NIH), Department of Health and Human Services (DHHS); Eric Benson, Glaxo Wellcome, Inc; Michele Bloch, MD, Consultant; Michael P Carson, MD, Division of General and Internal Medicine, University of Medicine and Dentistry of New Jersey (UMDNJ)-Robert Wood Johnson School of Medicine (RWJSM); Charlotte Catz, MD, National Institute of Child Health and Human Development (NICHD), NIH, DHHS; Carolyn Dresler, MD, SmithKline Beecham Consumer H, Carolyn Drest Consumer Healthcare (SBCH); George Gasparis, Office of the Director, NIH, DHHS; Harry Geyer, PhD, Center for Drug Evaluation and Research (CDER), Food and Drug Administration (FDA), DHHS; Michael G Greene, MD, American College of Obstetricians and Gynecologists (ACOG) and Department of Obstetrics and Gynecology, Harvard University; Ellen R Gritz, PhD, M.D. Anderson Cancer Center, University of Texas Health Sciences Center-Houston; Debra S Grossman, MA, National Institute of Drug Abuse (NIDA), NIH, DHHS; Deborah Haller, PhD, Department of Psychiatry, Virginia Commonwealth University; Sharon Hamm, PharmD, Elan Pharmaceutical Research Corporation; Corrine G Husten, MD, MPH, National Center for Chronic Disease Prevention and Health Promotion (NCCDPHP), Centers for Disease Control and Prevention (CDC), DHHS; Dou H Jean, PhD, CDER, FDA, DHHS; E Douglas Kramer, MD, CDER, FDA, DHHS; Indira Kumar, CDER, FDA, DHHS; Sandra L Kweder, MD, CDER, FDA, DHHS; Chang Qing Li, MD, DrPH, CDER, FDA, DHHS; Atkinson W Longmire, MD, CDER, FDA, DHHS; Cynthia G McCormick, MD, CDER, FDA, DHHS; Donald McNellis, MD, NICHD, NIH, DHHS; Cathy L Melvin, PhD, MPH, NCCDPHP, CDC, DHHS; BarCathy L Melvin, PhD, MPH, NCCDPHP, CDC, DHHS; Bar-
bara M Ostfeld, PhD, Department of Pediatrics, UMDNJ-RWJSM; Kathryn I Pollak, PhD, Department of Community and Family Medicine, Duke University; Angela C Ranzini, MD, Department of Obstetrics and Gynecology and Ranzini, MD, Department of Obstetrics and Gynecology and Reproductive Science, UMDNJ-RWJSM; Wendy Root, MPH,
ACOG; Jonelle Rowe, MD, NICHD, NIH, DHHS; David ACOG; Jonelle Rowe, MD, NICHD, NIH, DHHS; David
Schifkovitz, SBCH; Cora Lee Wetherington, PhD, NIDA, NIH, Schifkovitz, SBCH; Cora Lee Wetherington, PhD, NIDA, NIH,
DHHS; Celia J Winchell, MD, CDER, FDA, DHHS; Richard A Windsor, PhD, MPH, Smoke-Free Families Program, University of Alabama at Birmingham; Allison Wojciak, MPH, Association of Maternal and Child Health Programs.

1 Mullen PD. Maternal smoking during pregnancy and evidence-based intervention to promote cessation In: Spangler JG, ed. Primary care: clinics in office practice. Philadelphia: WB Saunders, 1999;26:577-89.

2 Marks JS, Koplan JP, Hogue CJR, et al. A cost-benefit/costeffectiveness analysis of smoking cessation for pregnant women. Am f Prev Med 1990;6:282-91.

3 Benowitz NL, Gourlay SG. Cardiovascular toxicity of nicotine: implications for nicotine replacement therapy. $\mathcal{F} \mathrm{Am}$ Coll Cardiol 1997;29:1422-31. 
4 Slotkin TA. Fetal nicotine or cocaine exposure: which one is worse? I Pharmacol Exp Ther 1998;285:931-45.

Levin ED, Slotkin TA. Developmental neurotoxicity of nicotine. In: Slikker W, Chang LW, eds. Handbook of developmental neurotoxicology. San Diego: Academic Press, 1998:587-615.

6 Roy TS, Andrews JE, Seidler FJ, et al. Nicotine evokes cell death in embryonic rat brain during neurulation. $f$ Pharmacol Exp Ther 1998;287:1135-44.

7 Slotkin TA. The impact of fetal nicotine exposure on nervous system development and its role in sudden infant death. In: Benowitz NL, ed. Nicotine safety and toxicity. New York: Oxford University Press, 1998:89-97.

8 Smoking Cessation Clinical Practice Guideline Panel and Staff. The Agency for Health Care Policy and Research smoking cessation clinical practice guideline 18, $7 A M A$ 1996;275:1270-80.

9 Wright LN, Thorp JM, Kuller JA, et al. Transdermal nicotine replacement in pregnancy: maternal pharmacokinetics and fetal effects. Am $\mathcal{f}$ Obstet Gynecol 1997;

10 Raw M, McNeill A, West R. Smoking cessation guidelines for health professionals. Thorax 1998;53:S1-38.

11 Hughes JR, Goldstein MG, Hurt RD, 2 . Recent advances in pharmacotherapy of smoking. ҒAMA 1999;281:72-6.

12 Benowitz NL. Nicotine replacement therapy during preg nancy. $\mathscr{F} A M A$ 1991;266:3174-7.

13 Briggs GG, Freeman RK, Yaffe SJ. Drugs in pregnancy and lactation: a reference guide to fetal and neonatal risk, 5 th ed. Baltimore: Williams \& Wilkins, 1998:xxii.

14 Medical Economics Company. Physicians' desk reference, 54th ed. Montvale, New Jersey: Medical Economics Company, 2000:1690.

15 Benowitz NL. Summary: risks and benefits of nicotine. In: Benowitz NL, ed. Nicotine safety and toxicity. New York: Oxford University Press, 1998:185-94.

16 Wisborg K, Jespersen L, Henriksen TB, et al. Nicotine patches to pregnant smokers - a randomized study. patches to pregnant smokers - a randomized study. Society for Research on Nicotine and Tobacco. Copenhagen, Denmark, August 23, 1998.

17 Oncken CA, Hatsukami DK, Lupo VR, et al. Effects of short-term use of nicotine gum in pregnant smokers. Clin Pharmacol Ther 1996;59:654-61.

18 Oncken CA, Hardardottir H, Hatsukami DK, et al. Effects of transdermal nicotine or smoking on nicotine concentrations and maternal-fetal hemodynamics. Obstet Gynecol 1997;90:569-74.

19 Ogburn PL, Hurt RD, Croghan IT, et al. Nicotine patch use in pregnant smokers-nicotine and cotinine levels and fetal effects. Am $\mathcal{F}$ Obstet Gynecol 1999;181:736-43.

20 Joseph AM, Norman SM, Ferry, et al. The safety of transdermal nicotine as an aid to smoking cessation in patients with cardiac disease. N Engl $\mathscr{f}$ Med 1996; 335:1792-8.

\section{Tobacco Control <http://www.tobaccocontrol.com>}

Visitors to the world wide web can now access Tobacco Control either directly by using its individual URL < http://www.tobaccocontrol.com> or through the BMJ Publishing Group's home page <http://www.bmjpg.com>. There they will find the following.

- Full text of all issues from Summer 1999 onward (open only to subscribers via password)

- Facility to send a rapid response to any article in the journal

- Contents lists of previous issues

- Members of the editorial board

- Subscribers' information

- Instructions for authors

- Details of reprint services.

A hotlink gives access to:

- BMJ Publishing Group home page

- British Medical Association web site

- Online books catalogue

- BMJ Publishing Group books

Suggestions from visitors about features they would like to see are welcomed. They can be sent to the editor at the email address on the inside front cover of this issue, or left via the opening page of the BMJ Publishing Group site or, alternatively, via the journal page, through "About this site". 